\title{
Weight-for-height and mid-upper-arm circumference should be used independently to diagnose acute malnutrition: policy implications
}

Emmanuel Grellety ${ }^{1 *}$ and Michael H. Golden²

\begin{abstract}
Background: Anthropometric surveys of children are used to assess the nutritional status of a population. World Health Organization (WHO) recommends that either mid-upper-arm circumference (MUAC) or weight-for-height Z-scores (WHZ) are used to assess acute malnutrition prevalence. However, there are reports from several countries that the two criteria identify different children. In order to examine the external validity of these observations we have compared the direction and degree of discrepancy across countries.

Methods: Anonymous data were collected from 1832 anthropometric surveys from 47 countries with measured children aged from 6 to 59 months and at least 75 malnourished subjects. The prevalence of total acute malnutrition and severe acute malnutrition was calculated using either absolute-MUAC or $\mathrm{WHZ}\left(\mathrm{WHO}_{2006}\right.$ standards). For each country, the total number of children diagnosed as acutely malnourished by either criterion alone or by both criteria were summed from all the surveys conducted in that country.

Results: In all countries a minority of children were diagnosed as malnourished by both criteria. Both the magnitude and direction of the discrepancy varied dramatically between countries with some having most children diagnosed as malnourished by MUAC and others where nearly all the children were diagnosed by WHZ alone. Eight additional countries with insufficient malnourished children were also analysed and they support the conclusions.

Conclusion: For all countries examined the discrepancy was not adequately explained by any single hypothesis, such as variation in relative leg to body length. The perceived need for humanitarian intervention can be affected by the measurement chosen to assess the prevalence of malnutrition which will vary from region to region. It is recommended that MUAC measurement be included in all anthropometric surveys and that the two criteria are not alternative measures of the loss of body tissue leading to an increased risk of death, but complementary variables that should both be used independently to guide admission for treatment of malnourished children.
\end{abstract}

Keywords: Survey, Nutrition, Acute malnutrition, Severe acute malnutrition, Mid-upper-arm circumference, MUAC, Weight-for-height, Wasting, Child, Human

\footnotetext{
* Correspondence: Emmanuel.Grellety.Bosviel@ulb.ac.be

${ }^{1}$ Research Center Health Policy and Systems - International Health, School of

Public Health, Université Libre de Bruxelles, Brussels, Belgium

Full list of author information is available at the end of the article
} 


\section{Background}

To estimate the nutritional status of a population anthropometric surveys are conducted. Where there is an excessive prevalence of malnutrition, or a deteriorating nutritional state, interventions are planned and implemented to prevent further deterioration and to identify malnourished individuals that require treatment. The relationship between subnormal anthropometric status and increased mortality is well established [1-4]. The prevalence of acute malnutrition in children is used internationally to define the risk of death and level of nutritional stress in a population leading ultimately to famine $[5,6]$.

The current definitions of acute malnutrition are based either upon a weight-for-height Z-score (WHZ) below -2 standard deviations of the international reference population (World Health Organization 2006 Growth Standards) or a mid-upper arm circumference (MUAC) lower than $125 \mathrm{~mm}$ [7]. These indicators are used independently to define the sum of moderate and severe acute malnutrition, commonly referred to as global acute malnutrition (GAM). Severe acute malnutrition (SAM) [8] is defined as the children with $\mathrm{WHZ}<-3$ SD or MUAC $<115 \mathrm{~mm}$. These cut-off points are used both to estimate the prevalence of malnutrition and also to identify those children who should be admitted for individual treatment of their acute malnutrition. The MUAC cut-off points were selected from statistical analysis of nutritional surveys to approximately correspond to the WHZ cut-off points so that the same prevalence of acute malnutrition would be found with each criterion.

As an individual looses weight, the tissue lost is mainly fat and muscle with relative preservation of the viscera. It has been tacitly assumed that the loss of these tissues from the carcass and from the upper arm is in proportion so that the two definitions of GAM and SAM should identify the same malnourished children. However, in practice, there is a discrepancy between the prevalence of children identified as malnourished by WHZ and by MUAC. In 2009, World Health Organization (WHO) estimated about a $40 \%$ overlap between the two indicators [8]. Since then there have been reports from individual countries indicating that the proportion of children identified by both criteria varies from country to country [9-12]. Among severely malnourished children hospitalized in rural Kenya, $65 \%$ of the WHZ $<-3$ SD SAM cases also had a MUAC $<115 \mathrm{~mm}$ and $56 \%$ of the MUAC $<115 \mathrm{~mm}$ SAM cases also had a $\mathrm{WHZ}<-3 \mathrm{SD}$ [9]. Overall $43 \%$ cases were identified by both indicators. Fernandez et al. reported that among 34,937 children between the ages of 6 and 59 months from 39 nutritional surveys $75 \%$ of the children with a WHZ $<-3 S D$ were not identified by a MUAC $<115 \mathrm{~mm}$ [10]. In Cambodia, this proportion was above $90 \%$, whereas $80 \%$ of $\mathrm{MUAC}<115 \mathrm{~mm}$ were not detected by WHZ $<-3 S D$ [11]. In South Sudan, Grellety et al. showed that $32 \%$ of deaths occurred in children admitted for treatment with a WHZ $<-3 S D$ but a MUAC of above $115 \mathrm{~mm}$ [12] so that they would have been denied treatment if only the MUAC criterion was used for admission.

Such discrepancy will result in divergent perceptions of the severity of a population's nutritional status and the need and scale of intervention required would depend upon which indicator is chosen to estimate the prevalence of malnutrition; consequent confusion amongst policy and decision makers about the appropriate criterion and response to acute malnutrition may delay and bias humanitarian aid delivery [13, 14]. On one hand, a strategy where the diagnosis can be based on either indicator, as recommended by some $[8,11]$, my unduly inflate the cost and workload of nutritional programmes whilst preventing few additional deaths and morbidity. On the other hand, relying on only one criterion may under-detect cases and deny treatment to a large proportion of the children at high risk of death $[11,12]$.

WHZ has been repeatedly criticized because it is affected by the body shape of the individual. In particular, ethnic groups, such as the Dinka/Nuar in South Sudan, with relatively long legs, as measured by sitting height/ total height ratio, will have a relatively low WHZ because more of their height is contributed by their legs which are lighter than their torso. Myatt et al. explains the lower prevalence using the MUAC criterion in pastoralist communities on this basis [15] and suggests that they are at relatively low risk of death and therefore can safely be excluded from treatment. However, recent evidence indicates that those with deficits in MUAC or WHZ carry the same risk of death, with those with both deficits having a higher risk [16]. On the other hand, because MUAC increases with age, when absoluteMUAC, un-standardised for the size of the child, is used as the criterion younger/smaller children will be more likely to be selected and older children who are also at risk of death may be excluded from treatment. This deliberate bias is justified on the grounds that younger children are inherently at a higher risk of death than older children; for this reason, most Non-Governmental Organizations (NGOs) and more latterly WHO recommend that both MUAC and WHZ are used as independent criteria for admission to feeding programmes [8]. In most populations, many nutritional surveys result in approximately the same prevalence of malnutrition using one or the other indicator, reinforcing the idea that the two indicators are alternative proxies for the same 
deficit. However, because of the ease of use of MUAC [17] and strong advocacy based mainly the relative sensitivity and specificity of WHZ and MUAC in predicting long-term all-cause mortality in the community, many organizations are now moving to MUAC-only programs [18]. Such a policy has distinct advantages, particularly the ability to screen children in the community, at the potential cost of excluding children, particularly older children, at high risk of death from malnutrition [12], for whom no simple community screening methods have been developed.

The actual degree and direction of discordance between different populations and countries is not well defined. Thus, as the two indicators appear to correlate poorly and the extant data comes from a limited number of countries, the objective of this study was to examine the relationship between the two criteria for admission in a large number of anthropometric surveys, with subjects randomly selected from the community, from around the world.

Regional differences potentially have a critical bearing on the perception of the severity of a population's nutritional status and the decision to intervene in a nutritional crisis, and consequently upon the program size and cost.

\section{Methods}

This study included data from 1832 surveys which had been conducted in 47 different countries in Africa (1619), Asia (166), Central America (2) and the Caribbean (45) between 1986 and 2014 and had a minimum of 75 malnourished children identified with the countries' combined surveys; 11 additional surveys from eight countries where few malnourished children were identified were also analysed.

Un-cleaned raw datasets of those anthropometric surveys which included all of the variables: age, sex, weight, height/length, MUAC and oedema, were obtained from the main agencies working in the field of international nutrition (NGOs, United Nations Agencies and Governments). Most of the surveys used two-stage cluster sampling with probability of being sampled proportional to the population; a few were systematic random samples of children where the total sampled population was limited (such as a refugee camp). All the agencies conducting these surveys routinely followed standard methods to taking weight, height and MUAC as recommended by WHO.

Any dataset that had been obtained with a sample size of less than 196 was not included, a priori, in the analysis. This sample size was chosen as sufficient to estimate a prevalence of $15 \%$ with a precision of $\pm 5 \%$ assuming a simple random sample.
The data were initially cleaned by deleting the records of individual children from the analysis with any of the following criteria:

1. Age $<6$ months

2. Age $>59$ months

3. Age, sex, weight, height, oedema or MUAC not recorded.

WHZ ( $\mathrm{WHO}_{2006}$ growth standards) and the other anthropometric indices were calculated using Emergency Nutrition Assessment (ENA) software for Standardized Monitoring and Assessment of Relief and Transitions (SMART) [19].

In each survey outliers were excluded using SMART flags; children with a weight-for-height which was more than 3.100 Z-scores above or below the survey's mean WHZ were excluded from the analysis on the basis that their weight or height were most likely to be incorrectly measured or recorded, or that they did not properly represent the population being surveyed. Similarly, children with a MUAC which, when compared with WHO standards of MUAC-for-age Z-scores (corrected for any height deficit) which was more than $3.100 \mathrm{z}$-scores above or below the survey's mean were also excluded. As WHO recommends only excluding children with values that are biologically implausible, the analysis was repeated excluding only those children whose WHZ or MUAC lay outside the limits specified by WHO.

GAM was defined as a weight-for-height of less than $-2.000 \mathrm{Z}$ score units or MUAC $<125 \mathrm{~mm}$ and SAM as a weight-for-height of less than $-3.000 \mathrm{Z}$ score units or a MUAC $<115 \mathrm{~mm}$.

All analyses were performed in $\mathrm{R}$ software version 2.9.2 [20].

\section{Ethics statement}

This is a secondary analysis of anonymous data where no individual, cluster or village location could be identified so that formal ethical clearance was not required. Permission to use and analyse the dataset was obtained from the organisations providing the raw datasets.

\section{Results}

Of the original $1,404,396$ children with plausible data in the 1832 surveys, $0.49 \%$ had been excluded for oedema and $1.4 \%$ were then excluded using SMART flags leaving a total of 1,384,068 children (see Additional file 1: Table S1). Table 1 shows the regions, countries, number of surveys from each country and the numbers of children that were included in the analysis. Most of the children (88.1\%) were from an African setting.

Overall $16.3 \%$ of children were identified as GAM by either $\mathrm{WHZ}<-2 \mathrm{SD}$ or $\mathrm{MUAC}<125 \mathrm{~mm}$ and 
Table 1 The regions, countries and numbers of surveys and children analysed

\begin{tabular}{|c|c|c|c|c|c|c|c|}
\hline Region & Country & Surveys No & Total children & Age $\%<26.5$ months & Age $\%>26.5$ months & Height $\%<88.5 \mathrm{~cm}$ & Height $\%>88.5 \mathrm{~cm}$ \\
\hline Latin America & Guatemala & 2 & 1393 & 44.7 & 55.3 & 74.4 & 25.6 \\
\hline Northern Asia & Tajikistan & 5 & 4446 & 45.1 & 54.8 & 63.6 & 36.4 \\
\hline East Africa & Malawi & 34 & 20014 & 44.4 & 55.6 & 72.1 & 27.9 \\
\hline East Africa & Mozambique & 14 & 3828 & 46.2 & 53.8 & 63.9 & 36.1 \\
\hline East Africa & Rwanda & 22 & 11968 & 36.1 & 63.8 & 62.5 & 37.5 \\
\hline Northern Asia & Afghanistan & 55 & 46217 & 40.9 & 59.1 & 66.4 & 33.6 \\
\hline Middle Africa & Angola & 45 & 37610 & 34.9 & 65.1 & 58.7 & 41.3 \\
\hline East Africa & Burundi & 32 & 20729 & 37.7 & 62.3 & 67.5 & 32.5 \\
\hline West Africa & Sierra Leone & 71 & 56482 & 41.7 & 58.3 & 61.7 & 38.3 \\
\hline East Africa & Zambia & 6 & 3447 & 41.0 & 59.0 & 61.6 & 38.4 \\
\hline East Africa & Uganda & 83 & 51526 & 46.7 & 53.3 & 64.4 & 35.6 \\
\hline East Africa & Tanzania & 13 & 6735 & 31.1 & 68.9 & 54.5 & 45.5 \\
\hline East Africa & Madagascar & 6 & 4092 & 42.5 & 57.5 & 62.2 & 37.8 \\
\hline West Africa & Ivory Coast & 6 & 7593 & 43.5 & 56.5 & 64.8 & 35.2 \\
\hline Middle Africa & DRC & 208 & 180795 & 43.9 & 56.1 & 68.3 & 31.7 \\
\hline West Africa & Liberia & 76 & 50409 & 37.5 & 62.5 & 57.7 & 42.3 \\
\hline Caribbean & Haiti & 45 & 35675 & 42.7 & 57.3 & 60.1 & 39.9 \\
\hline East Africa & Eritrea & 2 & 1597 & 35.9 & 64.1 & 50.5 & 49.5 \\
\hline Middle Africa & CAR & 49 & 36527 & 43.7 & 56.3 & 64.3 & 35.7 \\
\hline South Asia & Myanmar & 15 & 11144 & 43.3 & 56.7 & 69.3 & 30.7 \\
\hline West Africa & Guinea & 17 & 12691 & 44.0 & 56.0 & 63.9 & 36.1 \\
\hline South Asia & Pakistan & 27 & 24494 & 38.5 & 61.5 & 61.2 & 38.8 \\
\hline South Asia & Nepal & 7 & 4313 & 42.5 & 57.5 & 71.0 & 29.0 \\
\hline West Africa & Nigeria & 45 & 29769 & 42.8 & 57.2 & 62.3 & 37.7 \\
\hline East Africa & Zimbabwe & 3 & 1332 & 43.2 & 56.8 & 69.8 & 30.2 \\
\hline East Africa & Ethiopia & 73 & 63858 & 36.0 & 64.0 & 52.9 & 47.1 \\
\hline Sahel & Niger & 38 & 46784 & 45.3 & 54.7 & 66.6 & 33.4 \\
\hline South Asia & Bangladesh & 30 & 18304 & 36.8 & 63.1 & 63.5 & 36.5 \\
\hline Sahel & Somalia & 102 & 75717 & 40.8 & 59.2 & 54.4 & 45.6 \\
\hline Sahel & Chad & 128 & 90615 & 41.9 & 58.1 & 58.1 & 41.9 \\
\hline South Asia & Timor & 3 & 1673 & 38.7 & 61.3 & 58.3 & 41.7 \\
\hline Middle Africa & Cameroun & 9 & 5938 & 37.0 & 63.0 & 60.9 & 39.1 \\
\hline Sahel & South Sudan & 198 & 140046 & 44.1 & 55.9 & 52.1 & 47.9 \\
\hline West Africa & Benin & 7 & 7823 & 40.9 & 59.1 & 60.4 & 39.6 \\
\hline South Asia & India & 9 & 5649 & 39.3 & 60.7 & 63.2 & 36.8 \\
\hline Sahel & Sudan & 86 & 71796 & 37.2 & 62.8 & 51.8 & 48.2 \\
\hline West Africa & Burkina Faso & 67 & 41244 & 44.4 & 55.6 & 64.4 & 35.6 \\
\hline Sahel & Mali & 15 & 19668 & 43.7 & 56.3 & 58.8 & 41.2 \\
\hline Sahel & Mauritania & 51 & 40434 & 44.1 & 55.9 & 57.2 & 42.8 \\
\hline West Africa & Guinea-Bissau & 4 & 2414 & 45.5 & 54.5 & 61.6 & 38.4 \\
\hline West Africa & Togo & 14 & 6502 & 42.0 & 58.0 & 58.1 & 41.9 \\
\hline South Asia & Thailand & 2 & 1797 & 41.8 & 58.2 & 63.0 & 37.0 \\
\hline East Africa & Kenya & 49 & 33445 & 41.1 & 58.9 & 51.3 & 48.7 \\
\hline West Africa & Gambia & 8 & 6730 & 42.3 & 57.7 & 57.0 & 43.0 \\
\hline
\end{tabular}


Table 1 The regions, countries and numbers of surveys and children analysed (Continued)

\begin{tabular}{|c|c|c|c|c|c|c|c|}
\hline South Asia & Philippines & 7 & 3905 & 39.0 & 60.9 & 63.3 & 36.7 \\
\hline South Asia & Sri Lanka & 5 & 4576 & 39.6 & 60.4 & 56.4 & 43.6 \\
\hline Sahel & Senegal & 39 & 30324 & 43.4 & 56.6 & 55.8 & 44.2 \\
\hline Total & 47 & 1832 & 1384068 & $41.3 \pm 3.4$ & $58.7 \pm 3.4$ & $61.4 \pm 5.6$ & $38.6 \pm 5.6$ \\
\hline Caribbean & & 45 & 35675 & 42.7 & 57.3 & 60.1 & 39.9 \\
\hline East Africa & & 337 & 222571 & $40.2 \pm 4.8$ & $59.8 \pm 4.8$ & $61.1 \pm 7.2$ & $38.9 \pm 7.2$ \\
\hline Latin America & & 2 & 1393 & 44.7 & 55.3 & 74.4 & 25.6 \\
\hline Middle Africa & & 311 & 260870 & $39.9 \pm 4.6$ & $60.1 \pm 4.6$ & $63.1 \pm 4.2$ & $36.9 \pm 4.2$ \\
\hline Northern Asia & & 60 & 50663 & $43 \pm 2.9$ & $57 \pm 3$ & $65 \pm 2$ & $35 \pm 2$ \\
\hline Sahel & & 657 & 515384 & $42.5 \pm 2.6$ & $57.5 \pm 2.6$ & $56.8 \pm 4.7$ & $43.2 \pm 4.7$ \\
\hline South Asia & & 105 & 75855 & $39.9 \pm 2.1$ & $60 \pm 2.1$ & $63.2 \pm 4.6$ & $36.8 \pm 4.6$ \\
\hline West Africa & & 315 & 221657 & $42.4 \pm 2.2$ & $57.5 \pm 2.2$ & $61.2 \pm 2.8$ & $38.8 \pm 2.8$ \\
\hline \multicolumn{8}{|c|}{ Additional surveys with total number of GAM children $<75$} \\
\hline South Asia & Indonesia & 1 & 371 & 52.8 & 46.7 & 71.7 & 28.3 \\
\hline Middle Africa & Congo-B & 1 & 870 & 43.7 & 56.3 & 58.0 & 42.0 \\
\hline Latin America & Nicaragua & 2 & 962 & 33.8 & 66.3 & 56.9 & 43.1 \\
\hline Europe & Albania & 1 & 892 & 41.1 & 58.9 & 46.9 & 53.1 \\
\hline Europe & Macedonia & 1 & 845 & 40.7 & 59.3 & 45.7 & 54.3 \\
\hline Europe & Kosovar & 1 & 912 & 37.4 & 62.6 & 43.0 & 57.0 \\
\hline Latin America & Venezuela & 3 & 1771 & 39.3 & 60.7 & 50.5 & 49.5 \\
\hline Middle East & Syria & 1 & 522 & 39.6 & 60.4 & 49.9 & 50.1 \\
\hline
\end{tabular}

DRC Democratic Republic of Congo; CAR Central African Republic; Congo-B Congo Brazzaville

$3.5 \%$ as having SAM by either $\mathrm{WHZ}<-3 \mathrm{SD}$ or MUAC $<115 \mathrm{~mm}$.

With analysis of all the children from countries with more than 75 malnourished children, the proportion of overlap between the two indicators was $28.2 \%$ for GAM and $16.5 \%$ for SAM. Although the degree of overlap ranged from $15.0 \%$ in Sri Lanka to $38.5 \%$ in Sierra Leone for GAM (Table 2 and Fig. 1) and $6.1 \%$ in Sri Lanka to $29.8 \%$ in Mozambique for SAM (Table 3 and Fig. 2), for the 47 individual countries the degree of overlap was consistently low (GAM: $29.9 \pm 15.3 \%$, SAM $16.0 \pm 5.4 \%$, mean \pm SD); the overlap was much smaller for SAM than for GAM. When the 8 countries with few SAM children are included Guatemala and Thailand did not identify any children that satisfied both diagnostic criteria (Table 3). There were slightly fewer countries in this analysis that had a higher proportion of children malnourished by MUAC-only than by WHZ-only (GAM 19 vs 28 countries; SAM 18 vs 20). For GAM the degree of overlap between the criteria was slightly higher for those countries where MUAC-only diagnosed more children as malnourished than WHZ-only (overlap = $29.3 \pm 5.9 \%$ v $25.6 \pm 6.2 \%, p<0.05)$; for SAM there was no difference in the degree of overlap whether more children were diagnosed by MUAC or WHZ $(16.3 \pm 5.6$ vs $15.8 \pm 5.3, p=0.75)$.
The numbers of children diagnosed by one criteria or the other varied dramatically from one country to another. Tables 2 and 3 show the difference in the percent of malnourished children that are diagnosed by one criterion or the other. For GAM the difference ranged from minus-57 to plus-72\%; thus, in 11 countries more than $75 \%$ of malnourished children would be identified using MUAC only criteria, whereas in nine countries, including Philippines, Sri Lanka and Senegal less than $25 \%$ of malnourished children would be selected if only MUAC was used as the admission criterion.

For SAM the difference is even more dramatic. MUAC would not identify more than $75 \%$ of severely malnourished children in any country in which more than 75 SAM children identified; and only in Guatemala when the 47 countries are considered; however, in 4 of the 38 countries less than $25 \%$ of severely malnourished children would be identified and admitted for treatment if a MUAC only admission policy was being used. The situation is most dramatic in Sri Lanka and Senegal, where only 13 and $14 \%$ of SAM children would be found using a MUAC only strategy.

In analysis by country, if only one of the criteria were used to diagnose GAM then only $57 \pm 18 \%$ of the malnourished children would be identified by MUAC alone and only $70 \pm 15 \%$ by WHZ alone; this falls to 44 and 
Table 2 The diagnosis of GAM by WHZ, absolute-MUAC or by both criteria 47 countries with more than 75 GAM children and from 8 other countries

\begin{tabular}{|c|c|c|c|c|c|c|c|}
\hline Country & GAM subjects & $\begin{array}{l}\text { WHZ }<-2 \\
\text { only \% }\end{array}$ & $\begin{array}{l}\text { MUAC }<125 \mathrm{~mm} \\
\text { only } \%\end{array}$ & Both criteria \% & $\begin{array}{l}\text { \%WHZ minus } \\
\text { \%MUAC }\end{array}$ & $\begin{array}{l}\text { Total WHZ } \\
<-2 \%\end{array}$ & $\begin{array}{l}\text { Total MUAC } \\
<125 \mathrm{~mm} \%\end{array}$ \\
\hline Guatemala & 77 & 13.0 & 70.1 & 16.9 & -57.1 & 29.9 & 87.0 \\
\hline Tajikistan & 843 & 17.1 & 57.2 & 25.7 & -40.1 & 42.8 & 82.9 \\
\hline Malawi & 2343 & 20.5 & 59.5 & 20.1 & -39.0 & 40.5 & 79.5 \\
\hline Mozambique & 572 & 21.0 & 43.9 & 35.1 & -22.9 & 56.1 & 79.0 \\
\hline Rwanda & 1882 & 21.7 & 44.8 & 33.5 & -23.2 & 55.2 & 78.3 \\
\hline Afghanistan & 7628 & 22.6 & 43.7 & 33.7 & -21.1 & 56.3 & 77.4 \\
\hline Angola & 6053 & 23.5 & 45.6 & 30.9 & -22.2 & 54.4 & 76.5 \\
\hline Burundi & 3239 & 23.6 & 45.5 & 31.0 & -21.9 & 54.5 & 76.4 \\
\hline Sierra Leone & 9476 & 23.7 & 37.8 & 38.5 & -14.1 & 62.2 & 76.3 \\
\hline Zambia & 251 & 23.9 & 52.2 & 23.9 & -28.3 & 47.8 & 76.1 \\
\hline Uganda & 5790 & 24.4 & 46.1 & 29.4 & -21.7 & 53.9 & 75.6 \\
\hline Tanzania & 1034 & 25.9 & 37.4 & 36.7 & -11.5 & 62.6 & 74.1 \\
\hline Madagascar & 742 & 29.5 & 35.2 & 35.3 & -5.7 & 64.8 & 70.5 \\
\hline Ivory Coast & 644 & 30.9 & 36.6 & 32.5 & -5.7 & 63.4 & 69.1 \\
\hline DRC & 23416 & 32.6 & 42.7 & 24.6 & -10.1 & 57.3 & 67.4 \\
\hline Liberia & 6289 & 33.4 & 33.5 & 33.1 & -0.1 & 66.5 & 66.6 \\
\hline Haiti & 2415 & 33.8 & 40.5 & 25.8 & -6.7 & 59.5 & 66.2 \\
\hline Eritrea & 275 & 33.8 & 42.2 & 24.0 & -8.4 & 57.8 & 66.2 \\
\hline CAR & 3675 & 33.9 & 39.4 & 26.8 & -5.5 & 60.6 & 66.1 \\
\hline Myanmar & 2323 & 34.6 & 30.5 & 34.9 & 4.1 & 69.5 & 65.4 \\
\hline Guinea & 1014 & 36.0 & 34.6 & 29.4 & 1.4 & 65.4 & 64.0 \\
\hline Pakistan & 3769 & 36.8 & 35.2 & 28.0 & 1.7 & 64.8 & 63.2 \\
\hline Nepal & 1082 & 39.4 & 26.6 & 34.0 & 12.8 & 73.4 & 60.6 \\
\hline Nigeria & 3856 & 40.1 & 29.1 & 30.8 & 10.9 & 70.9 & 59.9 \\
\hline Zimbabwe & 128 & 41.4 & 32.8 & 25.8 & 8.6 & 67.2 & 58.6 \\
\hline Ethiopia & 10883 & 41.8 & 30.3 & 27.9 & 11.5 & 69.7 & 58.2 \\
\hline Niger & 7963 & 44.7 & 21.6 & 33.7 & 23.1 & 78.4 & 55.3 \\
\hline Bangladesh & 3321 & 46.8 & 25.2 & 28.0 & 21.5 & 74.8 & 53.2 \\
\hline Somalia & 19550 & 48.6 & 26.4 & 25.1 & 22.2 & 73.6 & 51.4 \\
\hline Chad & 17582 & 50.9 & 18.7 & 30.4 & 32.2 & 81.3 & 49.1 \\
\hline Timor & 285 & 51.2 & 20.7 & 28.1 & 30.5 & 79.3 & 48.8 \\
\hline Cameroun & 570 & 52.8 & 18.8 & 28.4 & 34.0 & 81.2 & 47.2 \\
\hline South Sudan & 33770 & 52.9 & 18.2 & 28.9 & 34.6 & 81.8 & 47.1 \\
\hline Benin & 652 & 53.7 & 19.5 & 26.8 & 34.2 & 80.5 & 46.3 \\
\hline India & 1498 & 54.9 & 11.7 & 33.4 & 43.3 & 88.3 & 45.1 \\
\hline Sudan & 15336 & 55.1 & 15.3 & 29.7 & 39.8 & 84.7 & 44.9 \\
\hline Burkina Faso & 5173 & 55.8 & 15.1 & 29.1 & 40.8 & 84.9 & 44.2 \\
\hline Mali & 2625 & 57.1 & 17.3 & 25.7 & 39.8 & 82.7 & 42.9 \\
\hline Mauritania & 4851 & 59.5 & 22.2 & 18.3 & 37.3 & 77.8 & 40.5 \\
\hline Guinea-Bissau & 147 & 60.5 & 19.0 & 20.4 & 41.5 & 81.0 & 39.5 \\
\hline Togo & 432 & 65.0 & 13.7 & 21.3 & 51.4 & 86.3 & 35.0 \\
\hline Thailand & 129 & 72.1 & 10.9 & 17.1 & 61.2 & 89.1 & 27.9 \\
\hline Kenya & 6657 & 72.9 & 11.1 & 16.0 & 61.8 & 88.9 & 27.1 \\
\hline
\end{tabular}


Table 2 The diagnosis of GAM by WHZ, absolute-MUAC or by both criteria 47 countries with more than 75 GAM children and from 8 other countries (Continued)

\begin{tabular}{|c|c|c|c|c|c|c|c|}
\hline Gambia & 738 & 73.7 & 7.2 & 19.1 & 66.5 & 92.8 & 26.3 \\
\hline Philippines & 325 & 76.6 & 7.4 & 16.0 & 69.2 & 92.6 & 23.4 \\
\hline Sri Lanka & 873 & 77.2 & 7.8 & 15.0 & 69.4 & 92.2 & 22.8 \\
\hline Senegal & 3648 & 78.4 & 6.8 & 14.8 & 71.6 & 93.2 & 21.6 \\
\hline Total/ $\%{ }^{\mathrm{a}}$ & 225824 & 43.8 & 28.0 & 28.2 & 15.8 & 56.2 & 43.8 \\
\hline Mean $\pm S D^{b}$ & - & $43 \pm 18$ & $29.9 \pm 15.3$ & $27.1 \pm 6.3$ & $28.6 \pm 20.4^{c}$ & $70.1 \pm 15.3$ & $57 \pm 18$ \\
\hline \multicolumn{8}{|c|}{ Countries with total number of GAM children in surveys $<75$} \\
\hline Indonesia & 74 & 27.0 & 51.4 & 21.6 & -24.3 & 48.6 & 73.0 \\
\hline Congo-B & 47 & 48.9 & 17.0 & 34.0 & 31.9 & 83.0 & 51.1 \\
\hline Nicaragua & 15 & 53.3 & 40.0 & 6.7 & 13.3 & 60.0 & 46.7 \\
\hline Albania & 43 & 55.8 & 18.6 & 25.6 & 37.2 & 81.4 & 44.2 \\
\hline Macedonia & 16 & 56.3 & 37.5 & 6.3 & 18.8 & 62.5 & 43.8 \\
\hline Kosovar & 14 & 57.1 & 21.4 & 21.4 & 35.7 & 78.6 & 42.9 \\
\hline Venezuela & 18 & 61.1 & 27.8 & 11.1 & 33.3 & 72.2 & 38.9 \\
\hline Syria & 25 & 72.0 & 16.0 & 12.0 & 56.0 & 84.0 & 28.0 \\
\hline
\end{tabular}

The data are presented as percent of the total number of GAM children fulfilling either WHZ or MUAC criteria $D R C$ Democratic Republic of Congo; CAR Central African Republic; Congo- $B$ Congo Brazzaville

${ }^{a}$ Total children with GAM and percent of all children in the database with that characteristic

${ }^{\mathrm{b}}$ The mean and SD of the 47 countries

ccalculated using absolute numbers

$56 \%$ when all the children in the 47 countries are considered. For SAM a MUAC-only policy would identify $55 \pm 19 \%$ and a WHZ-only policy $61 \pm 18 \%$ of severely malnourished children at immediate risk of death.

It should be noted that the proportions, and whether MUAC or WHZ diagnoses more children globally, are dependent upon the particular number of surveys from each country included in the analysis. Nevertheless, in this analysis there are more children identified as malnourished using WHZ than MUAC criteria (the reverse might have been found if the predominant number of surveys came from countries similar to Guatemala or Malawi).

As MUAC increases with age and height one would expect that surveys with an excess of young or short children would diagnose relatively more children by MUAC and those surveys with an excess of old or tall children would diagnose more children using WHZ. If the surveys had an even distribution of ages, half the children would be below and half above 26.5 months of age $(\{59-6\} / 2)$; according to the WHO standards, the height of a normal child of 26.5 months would be $88.5 \mathrm{~cm}$. Table 1 gives the proportion of children above and below 26.5 month and $88.5 \mathrm{~cm}$ in each country's surveys. Overall, only $41 \%$ of the children were younger than 26.5 months and in none of the countries did the percent of younger children reach $50 \%$; however, $61 \%$ of the children were shorter than would be expected for a normally grown child of 26.5 months, similarly in none of the countries did the percent of shorter children reach $50 \%$. These distributions could potentially influence the numbers of children diagnosed by MUAC-only or WHZ-only; albeit the age and length proportions of the children would have opposite effects upon the numbers diagnosed by each criterion.

Figure 3 shows the relationship between the proportion of younger children and the percentage of malnourished children who have a WHZ of $<-2$ and a MUAC of $\geq 125 \mathrm{~mm}$. There is no relationship between the age distribution of the children and the relative importance of WHZ or MUAC for diagnosis of GAM $\left(r^{2}=0.00\right)$. The age range of the children does not relate to the proportion or direction of the discrepancy in the diagnosis of GAM.

Figure 4 shows the relationship between the proportion of shorter children and the percent of malnourished children diagnosed by WHZ alone. There is a tendency for there to be fewer children diagnosed as GAM by WHZ when there are more short children. The regression is significant $\left(\mathrm{r}^{2}=0.19, P<0.01, \mathrm{y}=67.5-0.14 \mathrm{x}\right)$; there is a $10 \%$ decrease in the proportion of children diagnosed by WHZ with each $1.4 \%$ increase in the proportion of shorter children.

The result of reanalysis of the data using all plausible data i.e. using WHO flags and including all the children excluded by SMART flags are shown in the Additional file 1: Tables S1, S2 and S3. The results are similar to those presented with the SMART flags. 


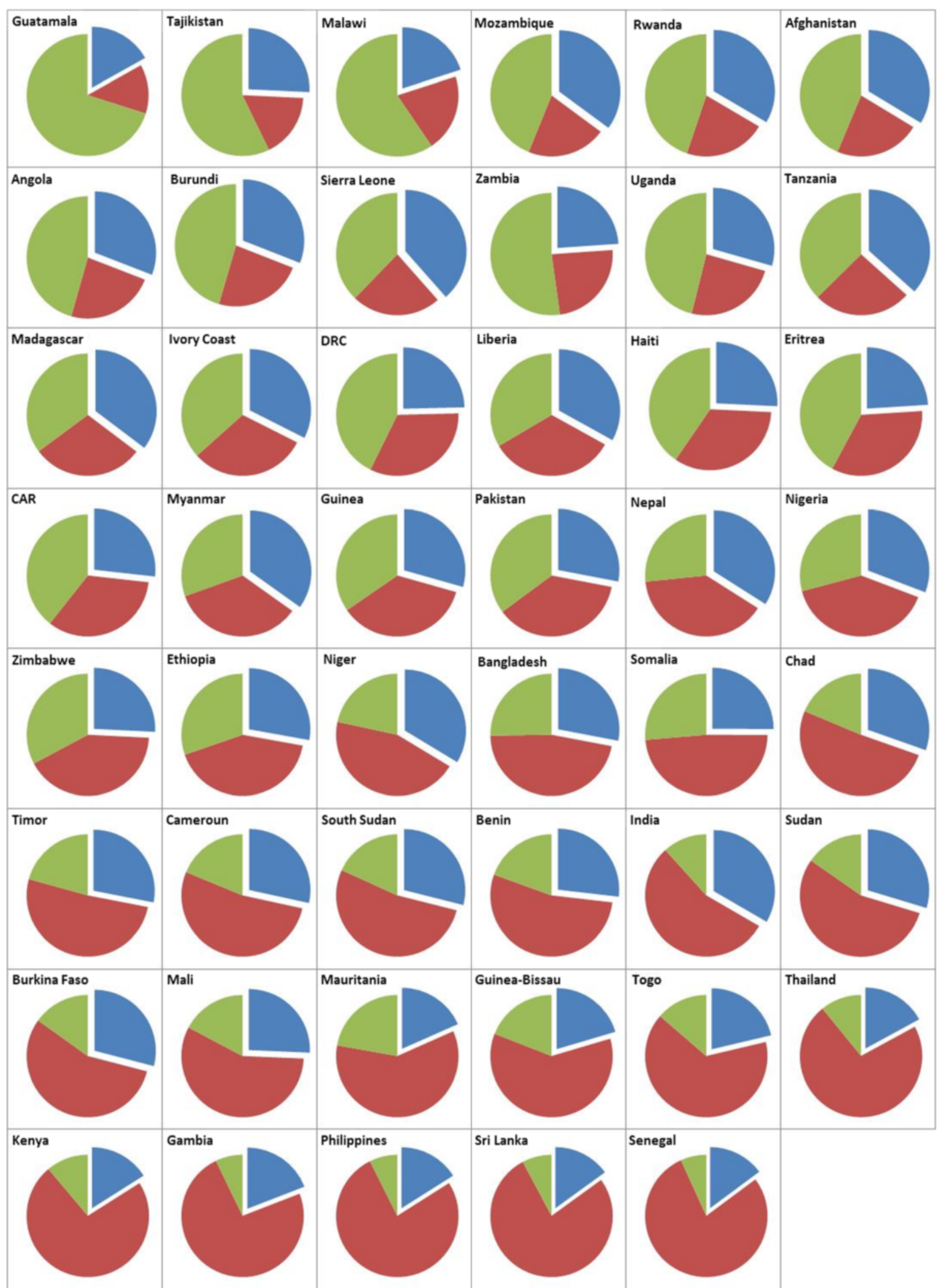

Fig. 1 Pie charts of individual countries showing the proportion of children with GAM diagnosed by both $M U A C<125 \mathrm{~mm}$ and $\mathrm{WHZ}<-2 \mathrm{SD}$ (blue) or by MUAC alone (green) or by WHZ alone (red) 
Table 3 The diagnosis of SAM by WHZ, absolute-MUAC or by both criteria in 38 countries with more than 75 SAM children and from 9 other countries

\begin{tabular}{|c|c|c|c|c|c|c|c|}
\hline Country & SAM subjects & $\begin{array}{l}\text { WHZ }<-3 \\
\text { only } \%\end{array}$ & $\begin{array}{l}\text { MUAC }<115 \mathrm{~mm} \\
\text { only } \%\end{array}$ & Both criteria \% & $\begin{array}{l}\text { \%WHZ minus } \\
\text { \%MUAC }\end{array}$ & $\begin{array}{l}\text { Total WHZ } \\
<-3 \%\end{array}$ & $\begin{array}{l}\text { Total MUAC } \\
<115 \mathrm{~mm} \%\end{array}$ \\
\hline Mozambique & 171 & 18.7 & 51.5 & 29.8 & -32.7 & 48.5 & 81.3 \\
\hline Malawi & 493 & 19.3 & 73.4 & 7.3 & -54.2 & 26.6 & 80.7 \\
\hline Tajikistan & 226 & 19.5 & 67.7 & 12.8 & -48.2 & 32.3 & 80.5 \\
\hline Ivory Coast & 106 & 25.5 & 62.3 & 12.3 & -36.8 & 37.7 & 74.5 \\
\hline Uganda & 1031 & 25.5 & 63.7 & 10.8 & -38.2 & 36.3 & 74.5 \\
\hline Rwanda & 491 & 26.1 & 51.3 & 22.6 & -25.3 & 48.7 & 73.9 \\
\hline Burundi & 734 & 26.3 & 57.9 & 15.8 & -31.6 & 42.1 & 73.7 \\
\hline Sierra Leone & 2585 & 26.3 & 51.4 & 22.2 & -25.1 & 48.6 & 73.7 \\
\hline Haiti & 329 & 27.4 & 60.5 & 12.2 & -33.1 & 39.5 & 72.6 \\
\hline Afghanistan & 1729 & 27.5 & 52.2 & 20.4 & -24.7 & 47.8 & 72.5 \\
\hline Madagascar & 163 & 28.2 & 54.6 & 17.2 & -26.4 & 45.4 & 71.8 \\
\hline Angola & 1456 & 28.7 & 56.0 & 15.2 & -27.3 & 44.0 & 71.3 \\
\hline Guinea & 158 & 29.1 & 53.8 & 17.1 & -24.7 & 46.2 & 70.9 \\
\hline CAR & 622 & 31.2 & 56.3 & 12.5 & -25.1 & 43.7 & 68.8 \\
\hline DRC & 4683 & 34.8 & 55.4 & 9.8 & -20.6 & 44.6 & 65.2 \\
\hline Tanzania & 255 & 35.7 & 42.7 & 21.6 & -7.1 & 57.3 & 64.3 \\
\hline Pakistan & 795 & 37.0 & 43.6 & 19.4 & -6.7 & 56.4 & 63.0 \\
\hline Liberia & 1383 & 39.3 & 45.5 & 15.3 & -6.2 & 54.5 & 60.7 \\
\hline Myanmar & 489 & 40.5 & 37.4 & 22.1 & 3.1 & 62.6 & 59.5 \\
\hline Nepal & 238 & 43.3 & 36.6 & 20.2 & 6.7 & 63.4 & 56.7 \\
\hline Ethiopia & 1973 & 43.4 & 41.0 & 15.6 & 2.4 & 59.0 & 56.6 \\
\hline Bangladesh & 532 & 44.7 & 42.5 & 12.8 & 2.3 & 57.5 & 55.3 \\
\hline Niger & 1537 & 50.7 & 25.4 & 23.9 & 25.4 & 74.6 & 49.3 \\
\hline Nigeria & 764 & 51.0 & 32.2 & 16.8 & 18.8 & 67.8 & 49.0 \\
\hline Chad & 3813 & 51.9 & 25.8 & 22.3 & 26.1 & 74.2 & 48.1 \\
\hline South Sudan & 8286 & 57.2 & 25.5 & 17.3 & 31.7 & 74.5 & 42.8 \\
\hline Somalia & 5541 & 57.4 & 28.9 & 13.6 & 28.5 & 71.1 & 42.6 \\
\hline Benin & 95 & 57.9 & 24.2 & 17.9 & 33.7 & 75.8 & 42.1 \\
\hline Burkina Faso & 916 & 58.7 & 23.0 & 18.2 & 35.7 & 77.0 & 41.3 \\
\hline Cameroun & 90 & 60.0 & 26.7 & 13.3 & 33.3 & 73.3 & 40.0 \\
\hline Sudan & 3312 & 60.5 & 19.2 & 20.4 & 41.3 & 80.8 & 39.5 \\
\hline Mauritania & 675 & 61.5 & 27.6 & 11.0 & 33.9 & 72.4 & 38.5 \\
\hline India & 341 & 61.6 & 15.5 & 22.9 & 46.0 & 84.5 & 38.4 \\
\hline Mali & 449 & 62.6 & 23.4 & 14.0 & 39.2 & 76.6 & 37.4 \\
\hline Kenya & 1156 & 77.7 & 12.9 & 9.4 & 64.8 & 87.1 & 22.3 \\
\hline Gambia & 112 & 78.6 & 10.7 & 10.7 & 67.9 & 89.3 & 21.4 \\
\hline Senegal & 534 & 86.0 & 6.7 & 7.3 & 79.2 & 93.3 & 14.0 \\
\hline Sri Lanka & 115 & 87.0 & 7.0 & 6.1 & 80.0 & 93.0 & 13.0 \\
\hline Total $/ \%^{\mathrm{a}}$ & 48697 & 47.3 & 36.3 & 16.5 & 11.0 & 63.7 & 52.7 \\
\hline Mean $\pm S D^{b}$ & - & $44.7 \pm 19.1$ & $39.3 \pm 18.2$ & $16 \pm 5.4$ & $31.4 \pm 19.4^{c}$ & $60.7 \pm 18.2$ & $55.3 \pm 19.1$ \\
\hline \multicolumn{8}{|c|}{ Countries with total number of SAM children in surveys $<75$} \\
\hline Guatemala & 14 & 7.1 & 92.9 & 0.0 & -85.7 & 7.1 & 92.9 \\
\hline Zambia & 44 & 15.9 & 77.3 & 6.8 & -61.4 & 22.7 & 84.1 \\
\hline
\end{tabular}


Table 3 The diagnosis of SAM by WHZ, absolute-MUAC or by both criteria in 38 countries with more than 75 SAM children and from 9 other countries (Continued)

\begin{tabular}{llllllll}
\hline Timor & 40 & 35.0 & 32.5 & 32.5 & 2.5 & 67.5 & 65.0 \\
Zimbabwe & 37 & 37.8 & 48.6 & 13.5 & -10.8 & 51.4 & 62.2 \\
Eritrea & 44 & 47.7 & 43.2 & 9.1 & 4.5 & 56.8 & 52.3 \\
Guinea-Bissau & 22 & 59.1 & 31.8 & 9.1 & 27.3 & 68.2 & 40.9 \\
Togo & 52 & 61.5 & 32.7 & 5.8 & 28.8 & 67.3 & 38.5 \\
Philippines & 51 & 78.4 & 15.7 & 5.9 & 62.7 & 84.3 & 21.6 \\
Thailand & 15 & 80.0 & 20.0 & 0.0 & 60.0 & 80.0 & 20.0 \\
\hline
\end{tabular}

The data are presented as percent of the total number of SAM children fulfilling either WHZ or MUAC criteria

$D R C$ Democratic Republic of Congo; CAR Central African Republic

${ }^{a}$ Total children with GAM and percent of all children in the database with that characteristic

${ }^{\mathrm{b}}$ The mean and SD of the 38 countries

ccalculated using absolute numbers

\section{Discussion}

There have been several reports showing a discrepancy between children who fall below the cut-off points for diagnosis of malnutrition using WHZ or MUAC criteria [8-14]. Our analysis, confirms that this is a general phenomenon across 1832 surveys from at least 47 different countries and that in all countries and surveys, the majority of children were malnourished by one or the other criteria, but not by both, and that the countries differ dramatically in which indicator identifies more children.

As an individual loses weight, the loss comes mainly from fat and muscle [21, 22]; intuitively such a loss should affect both the upper arm and the body as a whole. This begs the question as to why there is a universal discrepancy between the two criteria for diagnosis and why the direction of the discrepancy favouring one or the other criterion differs so markedly from one country to another.

First, part of the explanation must be related to the fact that, in contrast to WHZ, the diagnosis of acute malnutrition based on MUAC relies on a single absolute cut-off point independent of age, height and sex. As a child grows height, weight and MUAC all increase steadily albeit at different rates; children with exactly the same WHZ are more likely to fall below the absolute cut-off point for MUAC if they are shorter or younger. Thus, those diagnosed as malnourished by MUAC are likely to be substantially younger, on average, than those diagnosed as malnourished by WHZ [9, 12-14]. The relative proportions in each country will depend mainly upon the age-distribution of children included in the surveys, as well as the relative age-specific malnutrition rates. This is not an adequate explanation for the different directions of the discrepancy as the age categories did not differ significantly from one country to another in order to generate either the direction or degree of discrepancy observed (Fig. 3). There is no indication that those surveys where MUAC predominated included mainly younger children and those where WHZ predominated had older children. The relative proportions of children in the younger and older age groups were not sufficiently different between the countries despite the percent of GAM children diagnosed by WHZ alone varying from about 15 to almost $80 \%$.

Second, in countries where the children are more stunted (low height-for-age) a higher proportion of children will have a MUAC below the cut-off point at any particular WHZ prevalence simply because they are smaller. However, if poor nutrition affects both longitudinal and ponderal growth then a positive association between stunting and wasting would also increase the proportion of children with a low WHZ and ameliorate any discrepancy based upon stunting [9, 23]. Figure 4 shows the proportion of taller and shorter children in the surveys. There is indeed a tendency for those countries with a higher proportion of shorter children to have fewer children diagnosed as GAM by WHZ, and thus more by MUAC alone. However, the association is very weak with only about $19 \%$ of the variance explained on this basis. Stunting is therefore an inadequate explanation for the discrepancy for most countries or regions, for example in the Philippians, Thailand and GuineaBissau, $60-80 \%$ of the children were diagnosed by WHZ alone whereas in Tajikistan, Rwanda, Mozambique and Uganda less than $30 \%$ of GAM was identified by WHZ, despite the fact that all these countries, and many others, had about the same proportion of short children.

Third, WHZ may overestimate acute malnutrition in children with a low sitting-to-standing height ratio (SSR), i.e. with long limbs, and underestimate acute malnutrition in those with relatively short limbs, because the legs weigh less per unit length than the torso. Absolute-MUAC is less dependent on body proportions [15]. Thus, differences in SSR between populations might influence the diagnosis by WHZ and hence inflate 


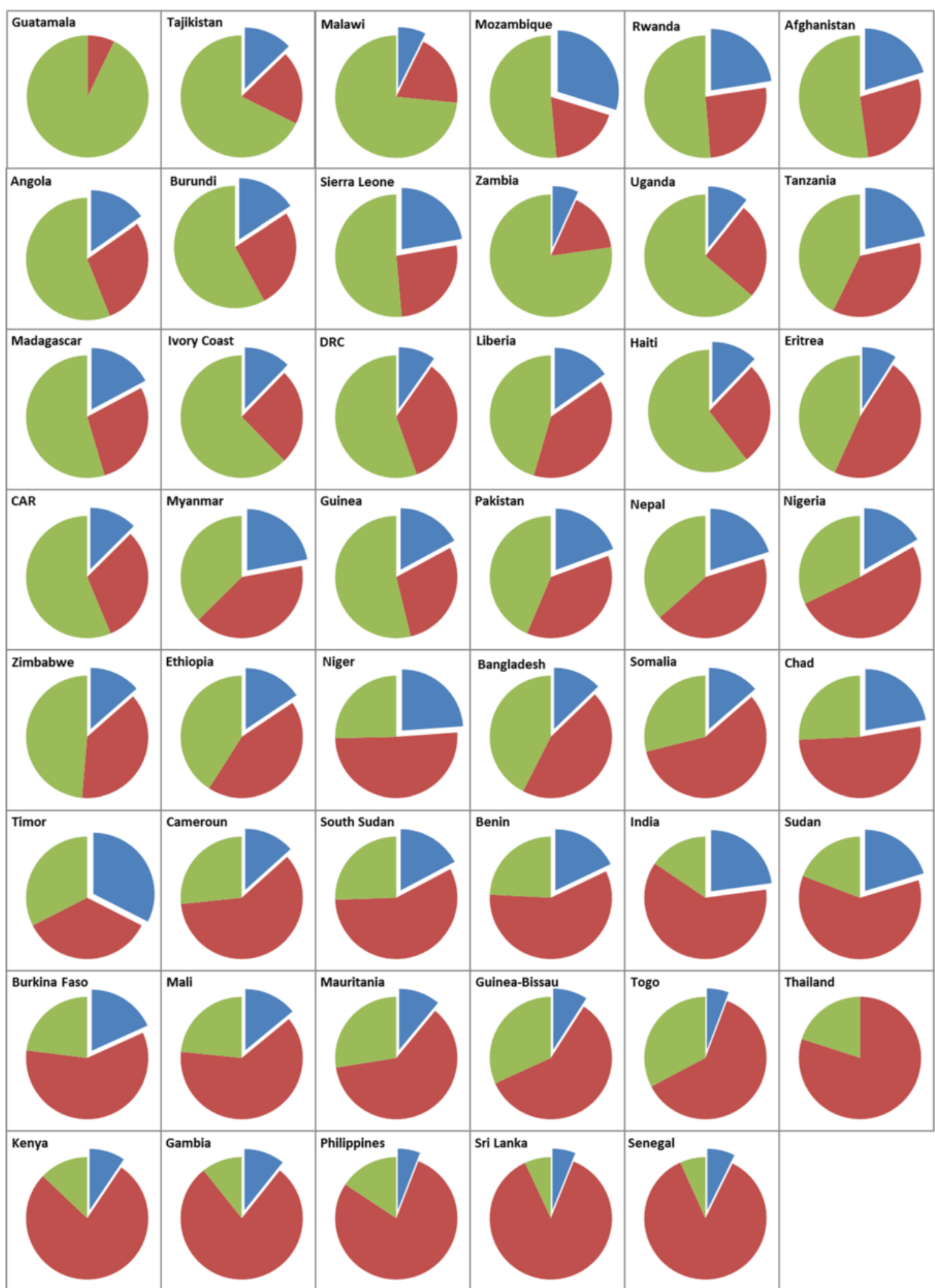

Fig. 2 Pie charts of individual countries showing the proportion of children with SAM diagnosed by both MUAC $<115 \mathrm{~mm}$ and WHZ $<-3 S D$ (blue) or by MUAC alone (green) or by WHZ alone (red) 


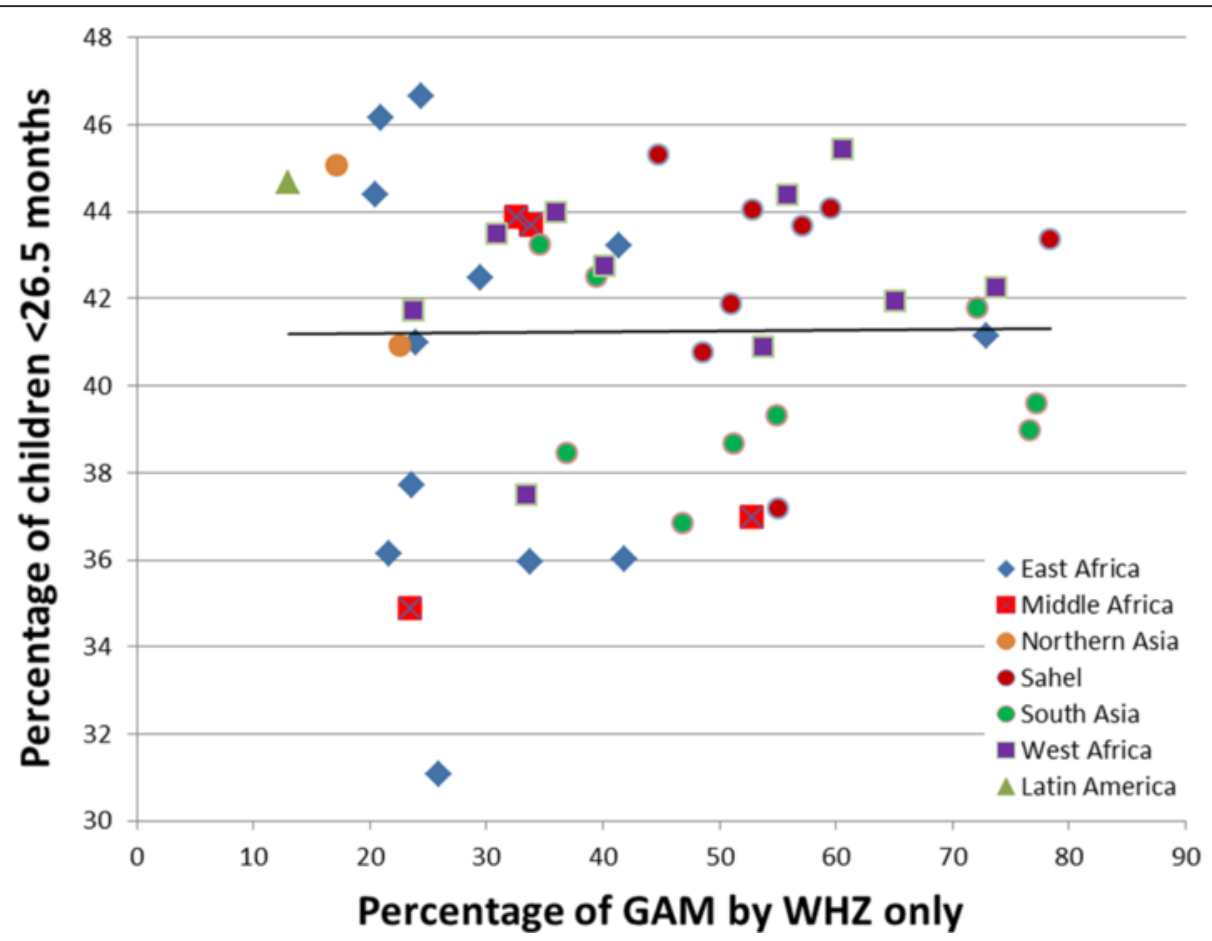

Fig. 3 The percent of children in each country below 26.5 months of age by the percentage of GAM children that are diagnosed as malnourished by the $\mathrm{WHZ}<-2.00 \mathrm{Z}$ criterion alone (i.e. with a MUAC of $\geq 125 \mathrm{~mm}$ )

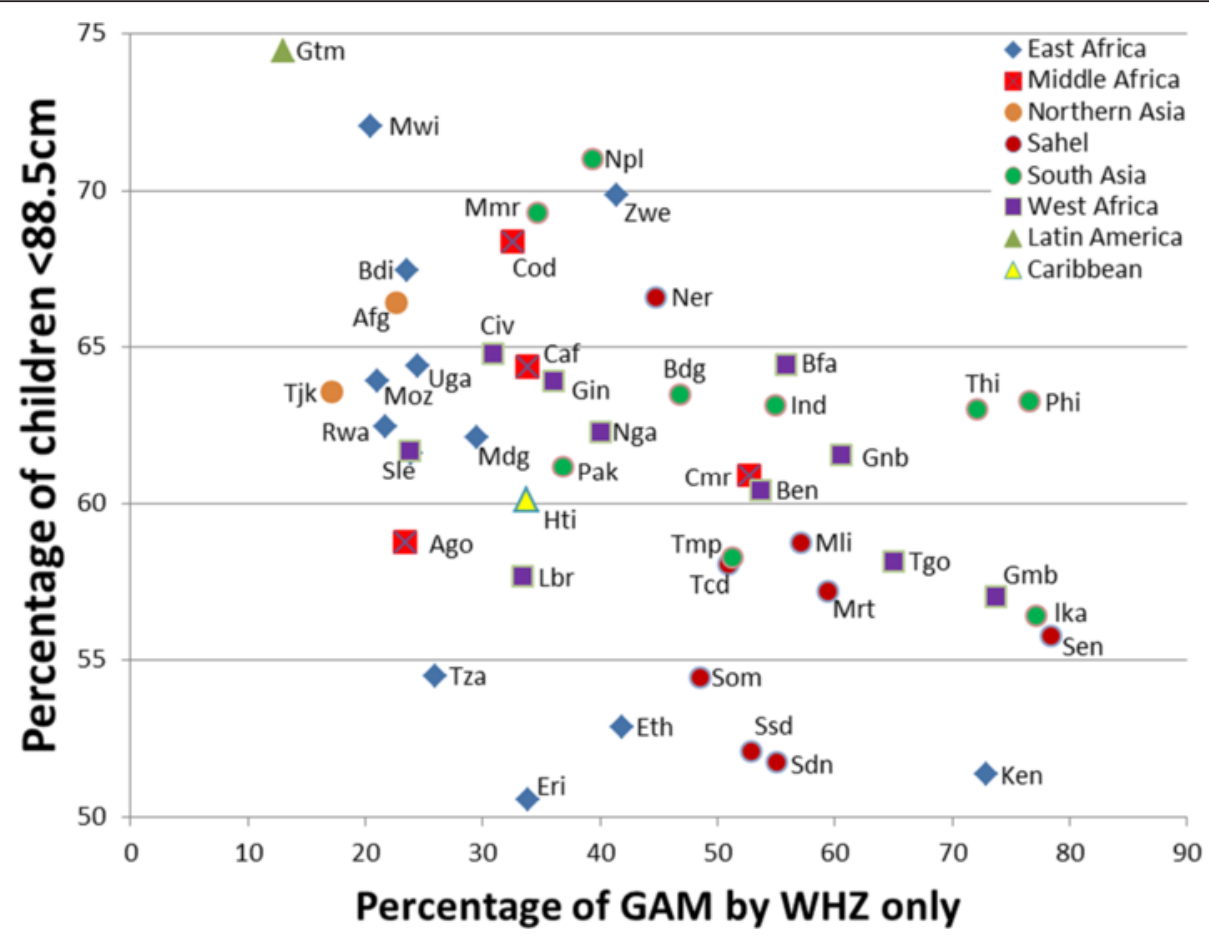

Fig. 4 The percent of children in each country (abbreviations are the United Nations 3-letter country identification codes) with a height below $88.5 \mathrm{~cm}$ by the percentage of GAM children that are diagnosed as malnourished by the $\mathrm{WHZ}<-2.00 \mathrm{Z}$ criterion alone (i.e. with a MUAC of $\geq 125 \mathrm{~mm}$ ) 
or deflate the prevalence in WHZ related malnutrition relatively independently of MUAC. The SSR of pastoralist populations is lower than in settled populations, particularly exemplified by the Dinka/Nuar tribes of South Sudan, but also to a lesser extent in other pastoralist populations of the Sahel. On the other hand, if malnutrition disproportionately affects the growth of the limbs rather than the body then WHZ may underestimate malnutrition in severely stunted populations. Similarly, individuals from cold climates tend to have shorter limbs than those from warm climates [24, 25].

If this phenomenon has a dominant effect upon the relation between MUAC and WHZ, then the difference in the proportions diagnosed by each criterion should correlate with the relative limb length of the children (SSR). Although there is a tendency for Sahalian countries to have fewer short children (Table 1, Fig. 4) and are more likely to have a higher proportion of the children diagnosed by WHZ (Table 2, Fig. 4) the relative leg length is not the main reason for the discrepancy as many authors assume. Thus, 14 countries have a higher proportion diagnosed by WHZ than South Sudan where the population is almost exclusively Dinka/Nuar; the archetypal long-limbed population (and if we include those surveys with few malnourished cases 6 of the 8 additional countries have a higher proportion of children diagnosed using WHZ than South Sudan). Although, several of these 14 countries in West Africa have mixed pastoralist/sedentary populations, in others such as India, Guinea-Bissau, Philippines, Thailand, and Sri Lanka the vast majority of children are diagnosed as GAM by WHZ alone. The available data suggests that the limbs of these latter children are not proportionately long and at least for these populations variation in limb length is an inadequate explanation for the much greater proportion of children diagnosed by WHZ and not by MUAC. This conclusion is supported by an analysis by Roberfroid et al [26]. They examined the relationship between WHZ and MUAC from 16 surveys in which sitting height had been measured and concluded that leg length had a minor effect upon the discrepancy and that other factors were dominant.

Forth, there are ethnic differences in fat distribution throughout the body in normally nourished populations living in the same environments [27-32]. In ethnic groups where fat is predominantly on the limbs rather than the torso it will increase MUAC relatively more than WHZ, whereas if it is predominantly truncal if will disproportionately increase WHZ. Although most data on ethnic fat-patterning comes from normally nourished and older individuals, to our knowledge the effect of malnutrition on the relative loss of fat from the limbs and trunk from any ethnic, age, sex, livelihood or disease grouping is unknown. Similarly, although MUAC is a relatively good indicator of total body fat in children, it is a poor indicator of fat-free tissue, mainly muscle [33], despite the assertions of the "muscle mass hypothesis" [34]. The various muscles lose different amounts of weight with malnutrition in animal studies [35] and clinically, muscle is mainly lost from the buttocks ("baggy pants") and shoulders, rather than from the arms. Whether different populations of children loose muscle disproportionately from various body muscles is unknown. Thus, both muscle and fat losses may affect MUAC and WHZ differentially; and, the assertion that the arm and the carcass should reflect loss of tissue proportionately would then be incorrect.

Fifth, in adults body shape can be divided into those with endomorphic, mesomorphic and ectomorphic body shapes depending upon the width of the trunk (limb girdles) [36]. If the children of Southern Asia and pastoralists are predominantly ectomorphic then this may partly explain why they have such a high prevalence using WHZ and not by MUAC; but this is unlikely to be the reason for the gross discrepancy between such countries as Guinea-Bissau and Benin versus Sierra Leone and Rwanda; the body habitus of each of these populations appears to be mesomorphic.

The relationship between MUAC and WHZ is clearly much more complicated than previously thought, and the contention that the variation is simply due to some populations having longer legs than others is not supported by the present data. Although it appears that none of these reasons for the discrepancy provide an adequate explanation for each of the anomalies, it is probable that each of the factors affects some of the populations, but not others, so that in combination they each can play a role in generating the discrepancy. However, apart from absolute-MUAC being more likely to identify younger and stunted children $[9,13,14]$, who are known to have an increased risk of death than older children, how each of the other factors affect the risk of death and serious side effects or complications from malnutrition needs to be determined before a decision is made to abandon WHZ as an independent criterion for the diagnosis of acute malnutrition.

The move towards using MUAC as the single criterion to admit severely malnourished children for treatment is partly based upon statistical analysis (receiver operating characteristic curves) of anthropometric indices against all-cause mortality in community studies over many ensuing months. These analyses show that MUAC has a better sensitivity and specificity than WHZ in predicting subsequent all-cause mortality of the individual child [37]. There are other cogent reasons for favouring MUAC such as its ease of use in the community [16]. However, both low MUAC and low WHZ are associated with an increased risk of subsequent death; albeit at least 
half the deaths are not related to anthropometric status $[1,16,38]$ and deaths due to accidents such as drowning are more likely in active well-nourished children. The slightly superior power of MUAC to predict which children will die would only be a strong argument for using only MUAC for identification of SAM and GAM children if they were both proxies for the same deficit and predicted the death of the same children. This appears not to be the case. If the two variables identify different children then the increased mortality associated with one deficit will be experienced by different children from the deaths associated with the other deficit. Thus, the present data suggest that the two indicators are complementary and additive rather than alternative measures that compete to identify the same individual children at increased risk of death. This is supported by the observation that children with both a deficit in MUAC and WHZ have a worse prognosis that those with a single anthropometric deficit [16]; furthermore addition of other deficits such as a low height-for-age or weight-forage progressively increase the risk of death confirming the additive effect of such deficits [39].

The countries of Southern Asia and the Sahel would appear to have a much higher prevalence of GAM if their nutritional status is assessed using WHZ than would occur if their nutritional status was assessed using absolute MUAC. On the other hand, countries of East and Southern Africa, and probably Latin America and Northern Asia would have a much higher prevalence of malnutrition if their nutritional status was assessed using absolute MUAC. Such differences in the way that the prevalence of malnutrition is assessed and the consequent perception of the severity of a situation are likely to affect the choices made by decision makers within National Governments, Donors, the United Nations system and implementing agencies to determine where they direct resources and the urgency and scale of the assistance given. The dramatic difference in prevalence between countries using the two diagnostic criteria is potentially critical in the distribution of resources. The national surveys conducted by Demographic and Health Surveys (DHS) [40] and, until recently, Multiple
Indicator Cluster Surveys (MICS) from United Nations International Children's Emergency Fund (UNICEF) [41], have been particularly influential in directing policy and aid. These agencies did not measure MUAC (or oedema [42]) in their subjects. This may have underestimated the degree and risk of death from acute malnutrition in those countries where the majority of malnourished children are identified as SAM and GAM using MUAC criteria and consequently directed aid elsewhere.

On the other hand, in terms of MUAC, many of the research studies have been conducted in Bangladesh, particularly for the longitudinal studies of mortality risk, and Malawi. In view of the current data it would be prudent to consider whether these studies are applicable globally (i.e. the external validity of the conclusions) and whether countries such as Sri Lanka, Philippines and Thailand should abandon the use of WHZ. Thus, in some countries, such as Malawi and Guatemala a move towards using MUAC only criteria would be justified as it identified most of the malnourished children, in other countries like those of the Sahel and Southern Asia, it would be appropriate to maintain $\mathrm{WHZ}$ as an independent admission criterion until the mortality risks are adequately assessed. However, some data are difficult to interpret; for example, why are the discrepancies so different in Myanmar and Thailand or Guinea-Bissau and Sierra Leone? We have no explanation for the generation of discrepancies between adjacent countries with similar ethnic groups.

\section{Limitations of this study}

This analysis was by country. Some countries are quite heterogeneous and there may be differences by region or sub-region within the country. For example, Southern India may approximate to the data collected from Sri Lanka whereas the data from Nepal, Pakistan or Bangladesh may be closer to data derived from Northern India; similarly, the data from costal West Africa may differ from the dry, inland pastoralist areas. By conflating national data any regional differences would be obscured. For example, Table 4 and Fig. 5 show the data

Table 4 The proportion of GAM children in 5 Ethiopian regions, diagnosed as malnourished by WHZ alone, absolute-MUAC alone or both criteria

\begin{tabular}{|c|c|c|c|c|c|c|}
\hline Ethiopia & Surveys & Total Subjects & GAM subjects & WHZ $<-2$ only $\%$ & MUAC < $125 \mathrm{~mm}$ only $\%$ & Both criteria \% \\
\hline SNNPR & 32 & 27721 & 4724 & $35 \%$ & $37 \%$ & $28 \%$ \\
\hline Amhara & 20 & 18256 & 3210 & $35 \%$ & $33 \%$ & $33 \%$ \\
\hline Oromia & 7 & 6170 & 709 & $42 \%$ & $30 \%$ & $28 \%$ \\
\hline Afar & 3 & 2555 & 368 & $47 \%$ & $27 \%$ & $26 \%$ \\
\hline Somali & 11 & 9154 & 1879 & $71 \%$ & $11 \%$ & $19 \%$ \\
\hline
\end{tabular}

The data are presented as percent of the total number of GAM children fulfilling either WHZ or MUAC criteria SNNPR Southern Nations, Nationalities, and Peoples' Region 


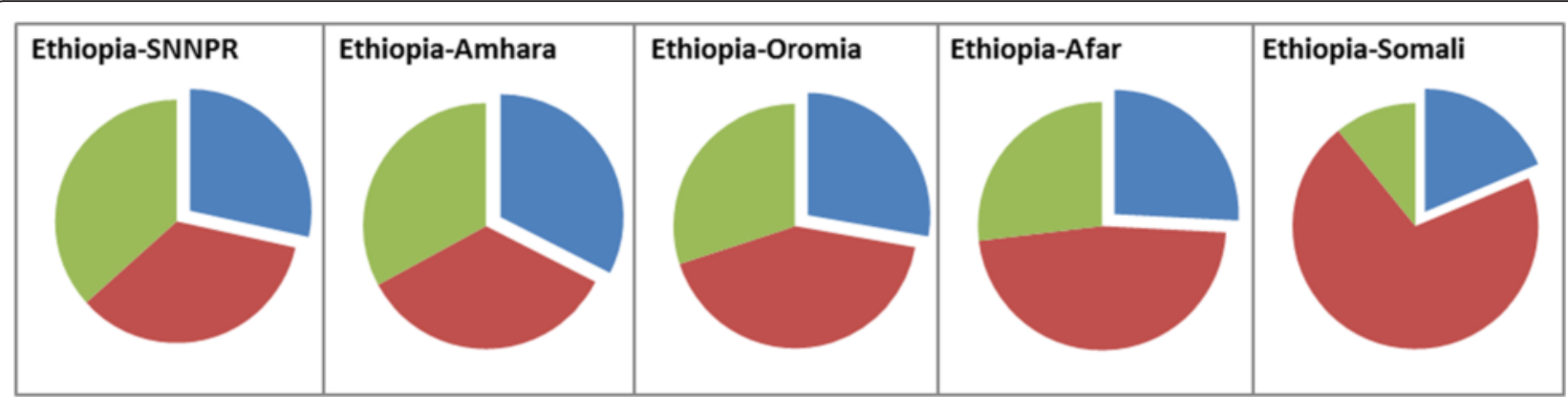

Fig. 5 Pie charts of 5 of the regions of Ethiopia showing the proportion of children with GAM diagnosed by both $M U A C<125 \mathrm{~mm}$ and WHZ $<-2 S D$ (blue) or by MUAC alone (green) or by WHZ alone (red)

from five regions of Ethiopia. There are regional differences. Somali region is predominated by WHZ whereas Southern Nations, Nationalities, and Peoples' Region (SNNPR) by MUAC. This has been explained on the basis of body shape of the Somalian ethnic group, however the Afar peoples are also asthenic pastoralists and their discrepancy is much closer to those of the Ethiopian highlands than of the Somali children. The interpretation of such differences cannot be due to single simplistic ideas. It will require many more surveys from other countries, from individual regions within countries and including other anthropometric measurements such as skin fold measurements and bone widths (or more sophisticated measurements of body composition), in different age/height groups, to determine the appropriate anthropometrics to define malnutrition.

These data are dominated by surveys from Africa and from areas requiring humanitarian intervention, some were from displaced populations. For this analysis the individual surveys have not been categorised into those from different livelihood areas. There are also insufficient data from the countries of South-East Asia, South and Central America and the regions of India to confirm or refute the findings from the relatively few countries included in this analysis from these continents.

\section{Conclusion}

There is great variation in the diagnosis of acute malnutrition using WHZ or MUAC in the developing world. In some the preponderance of children are diagnosed using WHZ and in others absolute-MUAC criteria. There are sufficient anomalous findings to make the extant hypotheses untenable to explain the differences between all the countries included in this analysis; in particular, relative leg length to body length does not appear to be a dominant factor in generating most of these regional differences.

As different children are selected using MUAC and WHZ, the data showing that slightly more children with a low MUAC are at risk of death than those with a low
WHZ should not be interpreted as being alternative proxies with MUAC being "superior"; rather, the two criteria are complementary with each selecting different children at increased risk of subsequent death in the community from malnutrition if untreated. As they are additive and not complementary it would be prudent to retain both criteria for admission to treatment programs. Further investigation is required to examine how variation in body shape, height, age and gender in these populations affect the relationship between absoluteMUAC and WHZ. Studies are also required to formally examine the pathophysiology and functional severity of the cases diagnosed by the different types of anthropometric deficits.

It is recommended that both criteria continue to be used for admission to therapeutic feeding and other programs aimed at alleviating malnutrition and preventing nutrition-related mortality. The move towards using MUAC only criteria may be appropriate for some countries but not for others where WHZ deficits predominate. In particular, countries of Southern Asia and the Sahel should maintain WHZ as an admission criterion as recommended by the WHO [8]; such decisions should be made by National Governments based upon their own anthropometric survey data.

As well as MUAC, simple screening tools for use in the community that identify individuals with a low WHZ but a normal MUAC need to be developed.

All future anthropometric surveys, including national DHS surveys, should include measurement of both MUAC and WHZ (and oedema) and the prevalence of GAM and SAM reported using both MUAC and WHZ; we also suggest that total-GAM and total-SAM prevalence estimates should be reported to include children who are diagnosed as malnourished by either criterion (and oedema for SAM cases). As different children are diagnosed with acute malnutrition using the two WHO recommended criteria, reporting the WHZ-only or MUAC-only prevalence will underestimate the problem with acute malnutrition in all countries surveyed; 
it appears to be a much more prevalent problem than previous reports and global databases of survey results would suggest.

\section{Additional file}

\section{Additional file 1: Supplementary tables $\mathrm{S} 1, \mathrm{~S} 2$ and $\mathrm{S} 3$, correspond to tables 1,2 and 3 in the paper; they show the data analysed using WHO flags (all plausible results) to exclude cases and the differences between the data analysed by WHO and SMART flags. (DOCX $97 \mathrm{~kb})$}

\section{Abbreviations}

DHS: Demographic and Health Surveys; ENA: Emergency Nutrition Assessment; GAM: Global Acute Malnutrition; MICS: Multiple Indicator Cluster Surveys; MUAC: Mid-Upper Arm Circumference; NGOs: Non-Governmental Organizations; SAM: Severe Acute Malnutrition; SMART: Standardized Monitoring and Assessment of Relief and Transitions; SNNPR: Southern Nations, Nationalities, and Peoples' Region; SSR: Sitting-to-standing height ratio; UNICEF: United Nations International Children's Emergency Fund; WHO: World Health Organization; WHZ: Weight-for-Height Z-score.

\section{Competing interests}

The authors declare that they have no competing interests.

\section{Authors' contributions}

EG \& MHG were involved in all stages from the conception and design, data acquisition, analysis and interpretation. Both authors approved the final version of the article.

\section{Acknowledgements}

We sincerely acknowledge all those individuals and organizations who have generously contributed anonymous survey data over the past 20 years. They come from 21 different organizations. These data were used to improve survey methods, develop the use of appropriate cleaning methods and examine the relationships between anthropometric variables. Most have indicated that they would prefer not to be individually acknowledged. Nevertheless, they have collectively made this work possible and improved the lives of the malnourished - for this we are truly thankful.

EG gratefully acknowledges the studentship provided by Nutriset. We would also like to thank Professor Philippe Donnen for all the assistance he has given to enable this work to be completed.

\section{Source of support}

Nutriset provided a PhD fellowship to Université Libre de Bruxelles in support of EG. Nutriset had no role in any aspect of this research including data collection, design, analysis, interpretation or writing the article. MHG received no support.

\section{Author details}

'Research Center Health Policy and Systems - International Health, School of Public Health, Université Libre de Bruxelles, Brussels, Belgium. ${ }^{2}$ Department of Medicine and Therapeutics, University of Aberdeen, Aberdeen, Scotland.

Received: 26 August 2015 Accepted: 30 January 2016

Published online: 05 February 2016

\section{References}

1. Pelletier DL. The relationship between child anthropometry and mortality in developing countries: implications for policy, programs and future research. J Nutr. 1994;124(10):2047S.

2. Pelletier DL, Frongillo JEA, Habicht JP. Epidemiologic evidence for a potentiating effect of malnutrition on child mortality. Am J Public Health. 1993;83(8):1130-3

3. Pelletier DL, Frongillo JEA, Schroeder DG, Habicht JP. The effects of malnutrition on child mortality in developing countries. Bull World Health Organ. 1995;73(4):443.

4. Pelletier DL, Frongillo EA. Changes in child survival are strongly associated with changes in malnutrition in developing countries. J Nutr. 2003;133(1):107-19.
5. IPC Global Partners. Integrated Food Security Phase Classification Technical Manual Version 2.0. Rome: The Food and Agriculture Organization of the United Nations; 2012. Available at http://www.ipcinfo.org/fileadmin/user_ upload/ipcinfo/docs/IPC-Manual-2-Interactive.pdf. Accessed 3 Feb 2016.

6. WHO. Manual on the management of nutrition in major emergencies IFRC/ UNHCR/ WFP/ WHO. Geneva: World Health Organization; 2000. Available at http://whqlibdoc.who.int/publications/2000/9241545208. pdf. Accessed 3 Feb 2016.

7. UNHCRWFP. Guidelines for Selective Feeding: the Management of Malnutrition in Emergencies. United Nations High Commissioner for Refugees; 2011. Available at http://www.unhcr.org/4b7421fd20.html. Accessed 3 Feb 2016.

8. WHO, UNICEF. WHO child growth standards and the identification of severe acute malnutrition in infants and children A Joint Statement by the World Health Organization and the United Nations Children's Fund; 2009. Available at http://www.who.int/nutrition/publications/severemalnutrition/978924159 8163_eng.pdf. Accessed 3 Feb 2016.

9. Berkley J, Mwangi I, Griffiths K, Ahmed I, Mithwani S, English M, et al. Assessment of severe malnutrition among hospitalized children in rural Kenya: comparison of weight for height and mid upper arm circumference. JAMA. 2005;294(5):591-7.

10. Fernández MÁL, Delchevalerie P, Van Herp M. Accuracy of MUAC in the detection of severe wasting with the new WHO growth standards. Pediatrics. 2010;126(1):e195-201.

11. Laillou A, Prak S, de Groot R, Whitney S, Conkle J, Horton L, et al. Optimal Screening of Children with Acute Malnutrition Requires a Change in Current WHO Guidelines as MUAC and WHZ Identify Different Patient Groups. PLoS ONE. 2014;9(7):e101159.

12. Grellety E, Krause LK, Shams EM, Porten K, Isanaka S: Comparison of weight-for-height and mid-upper arm circumference (MUAC) in a therapeutic feeding programme in South Sudan: is MUAC alone a sufficient criterion for admission of children at high risk of mortality? Public Health Nutr 2015;18:2575-81. http://dx.doi.org/10.1017/ S1368980015000737.

13. ENN, SCUK, ACF, UNHCR. Mid Upper Arm Circumference and Weight-forHeight Z-score as indicators of severe acute malnutrition: a consultation of operational agencies and academic specialists to understand the evidence, identify knowledge gaps and to inform operational guidance. Final review paper 2012. Available at http://www.cmamforum.org/Pool/Resources/ MUAC-WFH-Report-ENN-2013.pdf. Accessed 3 Feb 2016.

14. Roberfroid D, Hammami N, Lachat C, Prinzo ZW, Sibson V, Guesdon B, et al. Utilization of a Mid-Upper Arm Circumference Versus Weight-for-Height in Nutritional Rehabilitation Programmes: A Systematic Review of Evidence. Geneva: World Health Organization; 2013. Available at https://biblio.ugent.be/ input/download?func $=$ downloadFile\&recordOId $=5700355 \&$ fileOld $=5700357$. Accessed 3 Feb 2016.

15. Myatt M, Duffied A, Seal A, Pasteur F. The effect of body shape on weightfor-height and mid-upper arm circumference based case definitions of acute malnutrition in Ethiopian children. Ann Hum Biol. 2009;36(1):5-20.

16. Isanaka S, Guesdon B, Labar AS, Hanson K, Langendorf C, Grais RF. Comparison of Clinical Characteristics and Treatment Outcomes of Children Selected for Treatment of Severe Acute Malnutrition Using Mid Upper Arm Circumference and/or Weight-for-Height Z-Score. PLoS One. 2015;10(9):e0137606.

17. Myatt M, Khara T, Collins S. A review of methods to detect cases of severely malnourished children in the community for their. Putting the management of severe malnutrition back on the international health agenda. Food Nutr Bull. 2006;27(3):7.

18. Goossens S, Bekele Y, Yun O, Harczi G, Ouannes M, Shepherd S. Mid-upper arm circumference based nutrition programming: evidence for a new approach in regions with high burden of acute malnutrition. PLoS One. 2012;7, e49320. doi:10.1371/journal.pone.0049320.

19. Erhardt J, Seaman J, Golden M. Software for Emergency Nutrition Assessment (ENA for SMART). SMART 2011. Available at http://smartmethodology.org/ survey-planning-tools/smart-emergency-nutrition-assessment. Accessed 15 Aug 2015.

20. R Development Core Team. R: a Language and Environment for Statistical Computing. Vienna: R Foundation for Statistical Computing; 2004. Available at https://www.r-project.org. Accessed 3 Feb 2016.

21. Tanner CJ, Barakat HA, Dohm GL, Pories WJ, MacDonald KG, Cunningham $P R$, et al. Muscle fiber type is associated with obesity and weight loss. Am J Phys Endocrinol Metab. 2002;282(6):E1191-6. 
22. Ter Goon D. Fatness and fat patterning as independent anatomical characteristics of body composition: a study of urban South African children. Iran J Paediatr. 2013;23(4):423.

23. Dasgupta R, Sinha D, Jain SK, Prasad V. Screening for SAM in the community: is MUAC a simple tool? Indian Pediatr. 2013;50(1):154-5.

24. Katzmarzyk PT, Leonard WR. Climatic influences on human body size and proportions: ecological adaptations and secular trends. Am J Phys Anthropol. 1998;106(4):483-503.

25. Ruff C. Variation in human body size and shape. Ann Rev Anthropol 2002, 211-232.

26. Roberfroid D, Huybregts L, Lachat C, Vrijens F, Kolsteren P, Guesdon B. Inconsistent diagnosis of acute malnutrition by weight-for-height and midupper arm circumference: contributors in 16 cross-sectional surveys from South Sudan, the Philippines, Chad, and Bangladesh. Nutr J. 2015;14(1):86.

27. Wagner DR, Heyward VH. Measures of body composition in blacks and whites: a comparative review. Am J Clin Nutr. 2000;71(6):1392-402.

28. Deurenberg P, Deurenberg-Yap M. Validity of body composition methods across ethnic population groups. Acta Diabetol. 2003;40(1):s246-9.

29. Misra A. Impact of ethnicity on body fat patterning in Asian Indians and blacks: relation with insulin resistance. Nutrition. 2003;19(9):815-6.

30. Maligie M, Crume T, Scherzinger A, Stamm E, Dabelea D. Adiposity, fat patterning, and the metabolic syndrome among diverse youth: the EPOCH study. J Paediatr. 2012;161(5):875-80.

31. Stults-Kolehmainen MA, Stanforth PR, Bartholomew JB, Lu T, Abolt CJ, Sinha R. DXA estimates of fat in abdominal, trunk and hip regions varies by ethnicity in men. Nutrition \& Diabetes. 2013:3(3):e64.

32. Grijalva-Eternod CS, Wells JC, Girma T, Kæstel P, Admassu B, Friis H, Andersen GS. Midupper arm circumference and weight-for-length z scores have different associations with body composition: evidence from a cohort of Ethiopian infants. Am J Clin Nutr 2015;102(3):593-9. doi:10.3945/ajcn.114.106419.

33. Chomtho S, Fewtrell MS, Jaffe A, Williams JE, Wells JC. Evaluation of arm anthropometry for assessing pediatric body composition: evidence from healthy and sick children. Pediatr Res. 2006;59(6):860-5.

34. Briend A, Garenne M, Maire B, Fontaine O, Dieng K. Nutritional status, age and survival: the muscle mass hypothesis. Eur J Clin Nutr. 1989:43(10):715-26.

35. Spence CA, Hansen-Smith FM. Comparison of the chemical and biochemical composition of thirteen muscles of the rat after dietary protein restriction. Br J Nutr. 1978;39(03):647-58.

36. Carter JL, Heath BH. Somatotyping: development and applications (Vol. 5). Cambridge: Cambridge University Press; 1990.

37. Briend A, Maire B, Fontaine O, Garenne M. Mid-upper arm circumference and weight-for-height to identify high-risk malnourished under-five children. Maternal \& Child Nutrition. 2012;8(1):130-3.

38. Black RE, Allen LH, Bhutta ZA, Caulfield LE, De Onis M, Ezzati M, et al. Maternal and child undernutrition: global and regional exposures and health consequences. Lancet. 2008;371(9608):243-60.

39. McDonald CM, Olofin I, Flaxman S, Fawzi WW, Spiegelman D, Caulfield L, et al. The effect of multiple anthropometric deficits on child mortality: metaanalysis of individual data in 10 prospective studies from developing countries. Am J Clin Nutr. 2013:97(4):896-901.

40. The DHS Program: The Demographic and Health surveys Program. Available at http://www.dhsprogram.com. Accessed 3 Feb 2016.

41. UNICEF: Multiple Indicator Cluster Survey (MICS). Available at http://www. unicef.org/statistics/index_24302.html. Accessed 3 Feb 2016.

42. Frison $\mathrm{S}$, Checchi F, Kerac M. Omitting edema measurement: how much acute malnutrition are we missing? Am J Clin Nutr 2015, ajcn108282.

\section{Submit your next manuscript to BioMed Central and we will help you at every step:}

- We accept pre-submission inquiries

- Our selector tool helps you to find the most relevant journal

- We provide round the clock customer support

- Convenient online submission

- Thorough peer review

- Inclusion in PubMed and all major indexing services

- Maximum visibility for your research

Submit your manuscript at www.biomedcentral.com/submit
Biomed Central 